\title{
MINORIAS ÉTNICAS E EDUCAÇÃO: \\ O COLÉGIO ARNALDO JANSEN DE BELO HORIZONTE - MG (1912-1947)
}

Hercules Pimenta dos Santos*

RESUMO: O objetivo principal do presente artigo é abordar a discussão étnica que envolveu a referida instituição, constituída e mantida pela Congregação do Verbo Divino, originária da Alemanha. Para tanto, buscou-se realizar a reconstrução histórica da instituição escolar, seguindo uma abordagem metodológica que confluiu História da Educação, História Política e caminhou por um viés cultural observado nos conflitos de ordem étnica, social e religiosa vividos pelas comunidades de estrangeiros estudadas. Assim, buscou-se compreender como se deu o estabelecimento desse grupo de estrangeiros na, planejada e recém criada, capital mineira, concentrando o estudo nas relações entre estrangeirismos, educação, urbanização e religião. Constatou-se que, em determinados momentos, a presença desta escola foi rejeitada por parte da população local. Essa rejeição ocorreu apesar das propostas que moviam os missionários alemães fundadores do Colégio estar ligadas a questões de grande aceitação cultural.

Palavras-chave: Grupos Étnicos; Escolas Confessionais; Missionários Estrangeiros.

\footnotetext{
* Mestre em Educação pela Faculdade de Educação (FaE) da Universidade Federal de Minas Gerais (UFMG); Professor da Pósgraduação da Faculdade Milton Campos (FMC-MG). E-mail: herculessantos.ufmg@gmail.com
} 


\section{ETHNIC MINORITIES AND EDUCATION:}

THE ARNALDO JANSEN SCHOOL OF BELO HORIZONTE, MG (1912-1947)

ABSTRACT: The main objective of this paper is to address the ethnic discussion involving the aforementioned institution, which was established and maintained by the Congregação do Verbo Divino (Society of the Divine Word), from Germany. To reach this purpose, we sought to conduct the historical reconstruction of the school, based on a methodological approach that joined the fields of History of Education and History Politics, and to follow the cultural bias observed in the ethnic, religious and social conflicts experienced by the foreign communities studied. Thus, we sought to understand how the establishment of this group of foreigners took place in the planned and newly created capital of Minas Gerais, by focusing on the relations among foreign customs, education, urbanization, and religion. It was found that, at certain times, the local population rejected the presence of such school. This occurred in spite of the fact that the proposals that guided the German missionaries who founded the school involved issues of great cultural acceptance.

Keywords: Ehnic Groups; Religious Schools; Foreign Missionaries.

A temática trabalhada no presente artigo deriva da pesquisa de mestrado de minha autoria, finalizada em junho do ano de 2010: Católicos e protestantes: escolas confessionais fundadas por missionários estrangeiros, Belo Horizonte - MG (1900-1950). Este texto se desenvolve em torno de dois objetivos. O primeiro deles é desfazer o sigilo que condicionou a inclusão da escola confessional católica, de estatuto jurídico privado, Colégio Arnaldo Jansen de Belo Horizonte, na investigação maior, na qual foi denominada por CCAA, abreviatura de Colégio Católico de Ascendência Alemã. A quebra desse sigilo, exigido como condição para liberar acesso às fontes sobre a guarda da instituição, foi autorizada pela sua atual direção somente no ano de 2011. O segundo objetivo é retomar a discussão étnica que envolveu a referida instituição, constituída e mantida pela Congregação do Verbo Divino (CVD), originária da Alemanha. ${ }^{1}$ Para tanto, buscou-se realizar a reconstrução histórica dessa instituição escolar, seguindo uma abordagem metodológica que confluiu História da Educação e História Política e caminhou por um viés cultural observado na materialidade produzida pela instituição em foco, além dos conflitos de ordem étnica, social e religiosa vividos pela comunidade de estrangeiros estudada. Este estudo, em relação a instituições escolares, pautou-se pela linha de pensamento de Justino Pereira Magalhães (1998), que considera a instituição educativa uma complexidade espaço-temporal, pedagógica, 
organizacional, local de relações materiais e humanas, intercalando e projetando "futuro(s), (pessoais), através de expectativas institucionais" (MAGALHÃES, 1998, p.60-62). Dessa forma, considera-se a instituição escolar como um lugar de tensões permanentes, projetos elaborados e desenvolvidos a partir de quadros socioculturais, produzindo práticas e representações que "ampliam, complexificam, adaptam e recriam a cultura escolar” (MAGALHÃES, 1998, p.60-62). Instituições que, historicamente, recrutam seus públicos e cuidam deles de maneira criteriosa, "atendendo aos objetivos, aos estratos sócio-culturais envolventes, à capacidade de resposta [deste público]" (MAGALHÃES, 1998, p.60-62).

Buffa e Nosella (2006) chamam a atenção para a ocorrência de estudos que se preocupam com os sujeitos particulares às instituições escolares, não se ocupando de integrar à pesquisa a sociedade que a produziu. Uma sociedade que condiciona a criação e a manutenção de uma instituição de ensino pode-se constituir na condição de sua existência, determinando-lhe as relações de diversos tipos com a localidade onde está instalada. Rever a problemática da cidade, no contexto a ser estudado, permite conhecer as representações relacionadas à escola, seus sujeitos e sua relação com a sociedade local. Neste artigo, pretende-se explorar as relações da instituição em foco com o contexto político, social e cultural. Principalmente, por meio da focalização de problemas de imposição prescritiva que influenciaram nas dificuldades de inserção e manutenção em uma sociedade diferente, uma vez que seus sujeitos pretendiam a preservação de seus ideais culturais e educacionais de origem.

Sobre o acervo documental histórico do Colégio Arnaldo Jansen, após uma longa trajetória de contatos, foi concedida, à época, a permissão para o seu acesso nas condições já referidas. Por se tratar de uma instituição privada, as poucas informações encontradas fora do colégio não permitiam uma análise consistente de sua existência na capital mineira. A documentação que foi disponibilizada foi previamente analisada pela direção atual do colégio, que permitiu acesso apenas às seguintes fontes: Ata da Associação de Ex-alunos de 1946, Ata de Conferências de Professores do período 1921-1954 (contendo registros em língua alemã até 1944 e em português a partir de 1945), documentos diversos da Inspetoria do Ensino Secundário, além de alguns documentos oficiais. ${ }^{2}$ A documentação disponibilizada em maior quantidade constituiu-se de uma coleção do jornal publicado pelo colégio entre os anos de 1935 a 1945, 
faltando apenas uns poucos exemplares. Outro acesso permitido foi a um "livro de anotações" de tamanho grande, com seleção de recortes do Diário Oficial de diversos anos, contendo publicações sobre a área educacional. Documentos, de natureza oficial ou não, produzidos externamente a essa instituição e que foram confrontados com a produção material do Colégio se concentraram prioritariamente nos jornais de ampla circulação no período em que ocorreram as duas guerras mundiais da primeira metade do século XX.

\section{Minorias étnicas, religiosidade e educação}

A atuação da Igreja Católica perante a sociedade, por meio de suas instituições de ensino urbanas e rurais, adquiriu uma grande tradição educacional. No Brasil, ela foi "uma destinatária da educação dos índios e da abertura de colégios, até mesmo por sua condição, posta no ordenamento jurídico, de religião oficial do Reino e, depois, do Império” (CURY, 2005, p.7).

Com base na História da Educação, percebe-se ser bastante conflituosa a relação entre ensino público e privado, havendo a alternância dos personagens participantes desse conflito. No começo do século XIX, com o Estado imperial brasileiro decretando legalmente a partilha de sua responsabilidade pela educação escolar com a iniciativa privada, devido à impossibilidade financeira de prover sua universalidade, surge a escola privada e o início da expansão das escolas confessionais católicas. Seguidas por outras poucas confissões religiosas, as confessionais se concentram, preferencialmente, devido às limitações do Estado, no segmento secundário.

No final do século XIX, ocorre a separação entre Igreja e Estado, que tinha o Catolicismo como religião oficial, e o governo determina, então, a prática do ensino leigo nas escolas. Desse modo, a Igreja Católica deixa de ocupar um lugar vinculado ao poder político. Os ideais de uma sociedade laica pregados pelo novo regime influenciam nos quadros eclesiásticos, gerando crises internas e determinando uma busca por novas maneiras de difusão da fé e da doutrina cristã. $O$ ensino religioso assume um papel de vital importância nessa busca por um espírito católico da nacionalidade frente ao ensino laico. 
$\mathrm{Na}$ primeira metade do século XX, o ensino particular estava concentrado no ensino secundário, sendo confessional católico, em sua maioria. Durante as primeiras décadas do século XX, a Igreja Católica procurou restaurar sua autoridade nacional, abalada pelos novos ideais, crenças e religiões modernas, adotando como uma de suas estratégias a vinda de novas congregações religiosas de diversas regiões do planeta. ${ }^{3}$ Ao se instituir a República brasileira e com o fim do Padroado, tem-se a ocorrência de uma reviravolta na vida religiosa do país. Mesmo havendo a separação entre Igreja e Estado, muitas congregações provenientes da Europa abrem institutos no Brasil, objetivando o fortalecimento da fé cristã e o combate ao avanço do protestantismo.

Belo Horizonte é um lugar onde muitos estrangeiros escolheram viver, mesmo que não de maneira detidamente planejada, sendo, em muitos casos, fruto do acaso, de necessidades objetivas ou de demandas específicas. Alguns dos casos de interessados em vir para a cidade, com finalidade específica, são de religiosos e educadores, sendo essas funções geralmente exercidas pelas mesmas pessoas. A prefeitura praticou uma política de concessão de terrenos ${ }^{4}$ a várias entidades religiosas para que estas construíssem instituições de ensino, e, em troca, deveria ser disponibilizada uma quantidade predefinida de bolsas a estudantes sem recursos suficientes para arcar com os estudos. Os missionários que realizaram esses empreendimentos vieram principalmente da Europa e dos Estados Unidos.

É importante frisar que se torna necessário o cuidado de levar em consideração que os movimentos de colonização foram diferenciados quantitativamente entre Minas Gerais e o sul do país, pois, em Minas, eles não foram tão numerosos. Assim, pode-se afirmar que o estabelecimento dos contingentes estrangeiros em nosso estado foi elaborado de maneira diferente, quando relacionado aos processos coloniais de características étnicas mais acentuadas. ${ }^{5}$ A configuração das colônias, em Minas, demonstra uma especificidade étnica de menor impacto, pois sempre existiu a presença de brasileiros nessas colônias.

A imigração, na gênese da cidade, foi diluída em um fenômeno específico basicamente devido à dinâmica de sua criação e desenvolvimento. A cidade é marcada pela presença dos estrangeiros, da mesma forma que ela marcou suas vidas. A jovem capital mineira, hoje, em vias de completar seus 114 anos de existência, registra, em nomes de ruas, 
empresas, estabelecimentos comerciais e instituições diversas, a presença e a influência marcante dos estrangeiros. Essa importante presença histórica foi constituída em momentos que o outro, aquele que é considerado diferente por falar outra língua e possuir hábitos praticados em outras terras, causou estranhezas, fascinou, intrigou, fez pensar e agir por provocar admirações, repúdios e incertezas. São processos e experiências de pessoas que, ao penetrarem em outra cultura, suscitam mudanças, mas também são modificadas por elas.

Tratar das experiências dos estrangeiros é pensar o momento em que estes assumem tal condição, seu deslocamento, não apenas fisicamente, pois a "condição do imigrante estrangeiro instaura-se no deslocamento, não apenas no seu sentido físico, mas [também] social e cultural, uma vez que terá de iniciar uma busca por inserção na sociedade em que passará a viver" (PIMENTEL, 2004, p.17). Sua partida e sua chegada são geralmente permeadas pelas incertezas de um local novo, onde será preciso encontrar condições de estabelecimento, provisoriamente ou em definitivo, pois o fato de ser estrangeiro condiciona maneiras diferenciadas de vivências sociais. Para Fredrik Barth (1976), as fronteiras étnicas e os traços culturais não são fixos, o que importa é observar as peculiaridades das organizações e experiências vividas pelos grupos em contato com outros. A construção da identidade dos estrangeiros, participantes de uma comunidade maior, envolve negociações de limites e ou fronteiras de traços culturais compartilhados pelos sujeitos e os grupos em convivência. É necessário levar em consideração não apenas a imagem que os alienígenas têm de si e de sua comunidade, como também os olhares provenientes da sociedade acolhedora, pois isso é determinante dos repúdios e simpatias nas relações estabelecidas.

A partir dos anos de 1880, o Estado moderno se volta para o reforço dos sentimentos e dos símbolos nacionais, atribuindo novos valores ao uso da língua vernácula, às suas tradições, à religião, à história da nação e etnia. No rol das discussões em torno da temática nacionalista, destaca-se Benedict Anderson (2005), partindo do pressuposto de que a nação é uma comunidade imaginada. Para esse autor, se é difícil definir os termos "nação, nacionalidade e nacionalismo", analisá-los constituiu uma operação ainda mais complexa. Anderson procura definir a nação como uma comunidade política imaginada, ao mesmo tempo como intrinsecamente limitada e soberana. É imaginada, pois, por menor que seja a nação, 
seus membros "nunca conhecerão, nunca encontrarão e nunca ouvirão falar da maioria dos outros membros dessa nação, mas, ainda assim, na mente de cada um, existe a imagem de sua comunhão" (ANDERSON, 2005, p.25). É limitada, pois, ainda que possua grandes dimensões geográficas e seja constituída por milhares de sujeitos, suas fronteiras são finitas, mesmo que flexíveis. A nação é imaginada como soberana, pois ela tem a pretensão de ser livre e autônoma. Além disso, Anderson (2005) destaca que a nação é imaginada como uma comunidade que não leva em consideração as desigualdades internas, acreditando que seus membros estejam em harmonia.

O fenômeno nacionalista é historicamente situado na Revolução Francesa, caminhando de maneira paralela aos ideais liberais, democráticos e socialistas; constitui-se de maneira ideológica na Europa, fornecendo critérios e elementos para a legitimação e a formação dos Estados ${ }^{6}$ independentes. Para Montserrat Gibernau, "nacionalismo é o sentimento de [se] pertencer a uma comunidade cujos membros se identificam com um conjunto de símbolos, crenças e estilos de vida e têm a vontade de decidir sobre seu destino político comum” (GIBERNAU, 1997, p.36). O Estado procura fortalecer o vínculo entre seus cidadãos, tentando imprimir uma cultura única, expressa em símbolos e valores identitários comuns. Uma ideologia unificadora, com a nação fundamentando o sentimento de se pertencer "a um Estado em que a classe quer impor a todos os cidadãos a unidade de língua, de cultura e de tradições" (BOBBIO, 1995, p.800).

Entendendo o conceito de nacionalismo como a construção de um sentimento que elege os elementos inerentes à nação a que se vincula, política ou culturalmente, como únicos, observa-se a instituição de um forte aparato ideológico representado por um poder autoritário central. Ora se utilizando desse aparato ideológico, ora se valendo do uso de força repressora, esse poder político impõe à população o estabelecimento de uma ordem voltada para as ideias progressistas em defesa da produção econômica, além da unificação de pensamentos, símbolos e línguas, em detrimento de regionalismos e de tudo aquilo que é de origem estrangeira.

No Brasil, advém do século XIX o interesse em se construir uma identidade nacional. Assim, a instituição de simbolismos que pudessem ser absorvidos pela população brasileira se torna de fundamental impor- 
tância como forma de se mobilizar os sujeitos em volta dos ideais e de um imaginário ${ }^{7}$ nacionais. $O$ conceito de imaginário opera um sistema de representações elaboradas coletivamente, apoiadas em símbolos previamente sancionados pelo coletivo, que conferem sentido aos diversos aspectos da realidade, permitindo que os sujeitos se identifiquem entre si, o que torna possível a expressão de suas crenças e valores comuns. Essas interações definem posições de reação diante de conflitos e ameaças externas. O conceito de imaginário permite que se apreendam as representações que um determinado grupo social compartilha entre si e com seus diferentes, sem se tornar algo universal, pois são diferentes as representações elaboradas pelos indivíduos e variadas podem ser as combinações de representações dentro de um mesmo grupo.

Diante desse contexto, ao se elaborar um estudo que envolve estrangeiros e educação, torna-se necessária a explicitação da etnia e das características de seus principais elementos. De acordo com as ideias de Veiga e Rodrigues (2006), para se pensar algumas das configurações possíveis entre etnia, imigrantes e nacionalidade, é importante compreender a concepção de etnia como "condição relacional" de inserção ou de diferenciação dos sujeitos em seu universo social. As autoras Veiga e Rodrigues (2006) destacam que essa condição relacional é construída socialmente. Desse modo, o referencial teórico de autores como Norbert Elias, Poutignat e Streiff-Fenart e Lúcio Kreutz permite problematizar, por exemplo, que os grupos de imigrantes se constituíram enquanto grupos étnicos no Brasil por sua condição de estrangeiros. Isso é o que os caracteriza enquanto pertencendo a outra nacionalidade, considerando ainda que a diferenciação intergrupos permanecesse. As relações étnicas constituem interações e práticas sociais, promovendo transformações de suas características ao longo do tempo. Assim, a análise da educação, nas relações estabelecidas e mediadas pela etnicidade, tem lugar também na escola, vista como instituição social.

Pelas vias da etnia, etnicidade e grupos étnicos, adentra-se a discussões abrangentes, densas e por demais amplas. Os debates do século XIX tentaram responder a uma mesma pergunta: "como abranger princípios sobre os quais se fundam a atração e a separação das populações?" (POUTIGNAT; STREIFF-FENART, 1998, p.33). Respondendo a essa questão, Poutignat e Streiff-Fenart dizem que Vacher de Lapouge introduziu, nas ciências sociais, a noção de etnia, objetivando: 
[...] prevenir um "erro" que consiste em confundir a raça - que ele identifica pela associação de características morfológicas (altura, índice cefálico etc.) e qualidades psicológicas -, com um modo de agrupamento formado a partir de laços, intelectuais, como a cultura ou a língua (POUTIGNAT; STREIFFFENART, 1998, p.34).

Esses grupos sociais não poderiam ser confundidos com a "raça", uma vez que eram observados agrupamentos compostos por elementos de "raças" diferentes, submetidos sob o "efeito de acontecimentos históricos, as instituições, a uma organização política, a costumes ou ideias comuns" (POUTIGNAT; STREIFF-FENART, 1998, p.34).

O corolário das amplas discussões contidas no livro de Poutignat e Streiff-Fenart (1998) obriga a se fazer a tentativa de uma apropriação objetiva e delimitada desses conceitos. Entendo que etnicidade se refere aos povos, ${ }^{8}$ constituindo nações que se situam em "um estágio preliminar da formação da consciência nacional". Nessa concepção, as relações étnicas manifestam-se no confronto com os elementos estrangeiros, originando-se no sentimento xenofóbico. "Grupo étnico" é considerado, por esses autores, apenas como uma categoria descritiva e objetiva, percebida claramente por um observador externo, mais especificamente, pelas lentes de um antropólogo. É importante salientar que um engano comum a diversas pesquisas que versam sobre nação e nacionalismo é se tomar a nação como uma "realidade tangível", pois seu pressuposto é de uma consciência subjetiva e específica de um povo. Assim, "nacionalismo" é tido como uma das construções ideológicas do ideal de uma nação e, consequentemente, o "promotor da etnicidade".

Mesmo diante de uma considerável bibliografia ${ }^{9}$ debatedora do conceito de etnicidade, este geralmente é apresentado como uma categoria descritiva, que ajuda a pensar sobre problemas de integração nacional e assimilação de contingentes estrangeiros. $O$ conceito se refere a um conjunto de peculiaridades, ou de delineamentos, como língua falada, religião praticada e costumes, aproximando-se, nesse caso, da noção de cultura. Entendendo grupos étnicos como uma categoria definida pela atribuição e ou identificação dos próprios indivíduos a si mesmos, podendo também ser atribuída por outros sujeitos, a melhor conceituação do termo etnicidade, para Frederik Barth, ${ }^{10}$ é o de uma organização social que permite "descrever as fronteiras e as relações dos grupos sociais em termos de contrastes altamente seletivos, que são uti- 
lizados de forma emblemática para organizar as identidades e as interações" (BARTH apud POUTIGNAT; STREIFF-FENART, 1998, p.184).

Quando as comunidades que estabelecem afinidades de estranhamento entre si possuem cor de pele e outras características hereditárias diferentes, os problemas se concentram sob o rótulo de "problemas raciais". Quando se trata apenas de diferenças de ordem financeira, não interferindo nessas questões raça ou etnia, os problemas inerentes são tratados como "problemas de classe" e de "mobilidade social". Quanto às relações que envolvem os tensionamentos focalizados por esta pesquisa, ou seja, as diferenças de língua e tradições, sendo estas culturais, religiosas e/ou educacionais, por se tratar de contingentes estrangeiros, deparase com problemas que envolvem "minorias étnicas" (ELIAS; SCOTSON, 2000).

É importante informar que, em relação a um dos temas que compreenderam as discussões desta pesquisa, a saber, as políticas de nacionalização do ensino concentrado durante o período do Estado Novo, política esta que afetou consideravelmente as relações do Colégio Arnaldo Jansen com a comunidade mineira, não se tratou de um acontecimento propriamente inédito para aquele momento. Durante a Primeira República, o governo federal limitava-se a manter o ensino superior e a instrução secundária no Distrito Federal. Não houve a criação de estabelecimentos de ensino secundário nos estados. Menos ainda, houve alguma interferência no sentido de promover e melhorar o ensino primário. Nesse sentido, a única intervenção da União ocorre em 1918, em consequência da Primeira Guerra Mundial, ${ }^{11}$ pelo Decreto Federal de no 13.014, a 04 de maio daquele ano, com o governo substituindo escolas estrangeiras existentes no sul do país por "instituições nacionais".

Dessa forma, assume importância a relação educação/imigração, uma vez que esta é parte das discussões políticas no âmbito nacional e local, perpassando do Império à República. E também, na medida em que se insere no cenário político e social, a existência de escolas étnicas, de imigrantes, ou de colônias, adquirindo relevância para os estudos educacionais, apesar de esse tema representar uma lacuna na história da educação em Minas Gerais.

A escola, assumindo o lugar preponderante na educação do período republicano, determina processualmente um território no qual "a diferença étnica encontrará não só resistências, mas também tentativas de 
eliminação de valores culturais diferentes aos da nação brasileira a construir, interpondo-se aí a questão da nacionalidade como elemento formador e assimilador" (RODRIGUES, 2009, p.122). Para Rodrigues (2009), houve grande preocupação em relação à vinda dos imigrantes, deixando clara a perspectiva de transformar o Estado em um "centro de assimilação étnica." ${ }^{22}$ Com isso, seria necessário cuidar para se diversificar o contingente imigratório. O problema da "assimilação étnica" foi uma das preocupações maiores quanto à imigração em Minas por parte do governo. Assim, a variedade de origens seria uma das maneiras de se manter certo equilíbrio na disposição dessa população. Depositava-se na escolarização das classes populares, incluindo os estrangeiros, a formação de uma nação que se pretendia construir. A formação do caráter nacional seria fortalecida por intermédio da educação infantil, sendo, talvez, a melhor forma de assimilação. A escola aparece como uma das maneiras de se promover a assimilação dos imigrantes e estrangeiros, preparando-os para uma vida em acordo com a nova pátria. A tese de Rodrigues (2009) segue em afirmar que "este processo também diz respeito à educação das crianças filhas de imigrantes, considerando que parte destas crianças frequentou escolas públicas em Minas e que a questão da nacionalidade foi um dos pontos de tensionamentos com as autoridades da instrução" (RODRIGUES, 2009, p.119). Também as escolas particulares, sujeitas à fiscalização do governo, similarmente às públicas, foram alvo desses tensionamentos.

\section{Experiências de inserção e afirmação do Colégio Arnaldo Jansen de Belo Horizonte}

Objetivando servir aos filhos dos alemães de Santa Catarina, os missionários do Verbo Divino idealizaram a construção de seu primeiro colégio no Brasil. A instituição idealizada, em primeiro lugar, para a cidade de Desterro, depois na cidade de Brusque e em Florianópolis, no estado de Santa Catarina, não foi construída. Assim, o primeiro colégio sob direção dos verbitas instalado no Brasil, o Colégio Stella Matutina, foi fundado em Juiz de Fora no ano de 1901. O principal motivo da escolha desse local, como afirma a edição comemorativa de 87 anos do Colégio, estaria ligado à presença, naquela cidade, do colégio metodista Granbery, ${ }^{13}$ que, em uma demonstração dos embates entre católicos e protestantes, 
"assustava um pouco os católicos da cidade, sobretudo depois que o próprio vigário se convertera ao protestantismo" (CANÇADO, 1999, p.25). Nesse período, existiam apenas esses dois educandários masculinos na cidade. Um dos anseios dos católicos de Belo Horizonte era o de estabelecer um colégio masculino católico, tendo como parâmetro o Granbery, de Juiz de Fora. No início do ano de 1912, o conselho provincial da Congregação, reunido na cidade de Juiz de Fora, determinou que se alugasse um imóvel na capital mineira para a abertura de uma instituição de ensino.

Objetivando solucionar o problema da demanda de espaço devido ao crescente número de alunos matriculados na instituição no decorrer dos meses, as atenções dos clérigos da CVD se voltaram para as instalações que seriam destinadas à Exposição Permanente do Estado, estrutura situada, conforme endereçamento da época, entre as Ruas Ceará, Timbiras e as avenidas Paraibuna e Silviano Brandão.

Um personagem importante para os padres da CVD, quanto à aquisição do imóvel, foi o Senador Bernardo Monteiro, que, hoje, dá nome a uma das ruas laterais do Colégio, a antiga Paraibuna. Conforme relatam, "sempre com esperança de um dia poder contar com condições mais auspiciosas, o Senador Dr. Bernardo Monteiro respondeu negativamente a diversos pedidos no sentido de adquirir o prédio $^{14}$ em questão para outros fins não menos importantes e simpáticos" (LAR Católico, 1945, p.25). De acordo com o relato existente na publicação consultada, em relação aos ideais do senador para a concessão das instalações, foi indeferido o requerimento feito pela Prefeitura da capital mineira para a instalação naquele local da Escola Normal. O mesmo aconteceu com o intuito do Dr. Hugo Werneck de destinar o local à edificação de uma Faculdade de Medicina, o que poderia ser considerado como duas importantes contribuições para a cidade há tão poucos anos inaugurada.

Em 10 de dezembro de 1912, sem a explicitação dos motivos que levaram o Senador a optar por beneficiar os planos da Congregação, como a publicação dos verbitas informa, a Prefeitura comunicou a cessão oficial da estrutura existente. Apresentada a planta dos edifícios a serem construídos, em 15 de maio de 1913, foi celebrado o contrato ${ }^{15}$ definitivo de cessão gratuita da Exposição Permanente, feita pela Prefeitura municipal à Sociedade Propagadora de Ciências e Artes, então título civil da CVD. Conclui-se, então, que, em relação à preferência dada por Bernardo 
Monteiro ao projeto dos padres da CVD, está o fato de que, além de Belo Horizonte ganhar uma instituição de ensino nos moldes predeterminados, a ideia do Senador a respeito de uma Exposição Permanente dos produtos do subsolo mineiro também seria materializada.

Intelectuais considerados de renome "atenderam ao convite do diretor e de bom grado se inscreveram na lista dos professores do Colégio" (LAR Católico, 1945, p.26). O corpo docente já contava, nos primeiros anos de existência do CCAA, com nomes como Lúcio José dos Santos, Mário de Lima, Afonso de Morais e Francisco Magalhães, ${ }^{16}$ "um corpo docente dos mais abalizados, do qual fazem parte varios dos mais illustres e conceituados professores, brasileiros natos" (IMPRENSA Official, 1920, p.16). No ano de 1920, o corpo docente era formado por clérigos, em número de sete, e professores leigos, composto por nove lentes; as matérias ministradas eram: Religião, Francês, Aritmética, Álgebra, Física, Química, Cosmografia, Latim, Inglês, Geografia, Desenho, Caligrafia e Geometria, Histórias Geral, do Brasil, Pátria e Natural, e Língua Portuguesa. A matéria de Religião era ministrada por quatro clérigos diferentes, entre eles, o reitor, o vice-reitor e o prefeito da instituição, os quais, além dessas, ministravam também outras disciplinas.

Realizar a análise da cultura escolar de uma instituição de ensino se configura, de alguma maneira, no processo de exame da produção e circulação de modelos culturais próprios de cada escola, propiciado pelo contato com a sua materialidade produzida, o que possibilita a reconstrução de grande parte do cotidiano dessa escola. Essa materialidade, citando apenas alguns de seus elementos, é encontrada em publicações de circulação interna, cadernetas escolares, atas de reuniões administrativas e pedagógicas; programas de disciplinas, regimento interno, livros de matrículas, livros didáticos adotados ou produzidos; fotografias, mobiliário e arquitetura escolar, não se esgotando nestes. O desenvolvimento de ações, suscitadas por uma ordem prática, pelos sujeitos escolares, dentro das instituições de ensino, é tema de grande interesse para a pesquisa histórica educacional. São ações realizadas pelos seres históricos, dia após dia, capazes de produzir alterações de grande importância no âmbito educacional. Para Dominique Julia (2001), a cultura escolar compreende "um conjunto de normas que definem conhecimentos a ensinar e condutas a inculcar, e um conjunto de práticas que permitem a transmissão desses conhecimentos e a incorporação desses comportamentos" (JULIA, 2001, p.10). 
Dessa forma, compreende questões que se desenvolvem permeadas pela cultura do cotidiano da escola e de seus sujeitos, como o alunado, o professorado, a direção e o corpo administrativo, além da sua indissociável relação com a comunidade local e regional, assuntos prioritariamente focados por este estudo histórico.

Como geralmente adotam as instituições de ensino de cunho religioso, o CCAA se fundamentava nos princípios de uma disciplina severa, de autoridade e obediência. Conforme análise feita do livro de atas de reuniões de professores, ${ }^{17}$ período de 1921 a 1954, as cobranças pairavam desde a postura do professor e do aluno em sala de aula e fora dela, até a preparação das aulas e matérias ministradas.

Pode-se dizer que, de alguma forma, e em alguns momentos, a escola aqui escolhida para a realização de uma construção histórica de sua trajetória em Belo Horizonte foi rejeitada por parte da população local. Apesar de a proposta que moveu os missionários que constituíram o Colégio Arnaldo Jansen ter sido ligada a questões de grande aceitação cultural, como uma educação capaz de promover um bom desenvolvimento da capacidade intelectual e moral de seu alunado, além das ações evangelizadoras, alguns fatores colaboraram para que esses motivos fossem relegados a um segundo plano. Pesaram, frente aos motivos anteriores, questões de dissidência política relacional, ${ }^{18}$ que influenciaram fortemente o imaginário e a aceitação cultural por parte da população local.

Alguns dos problemas vivenciados pelos estrangeiros de proveniência alemã, em Belo Horizonte, aparecem ligados aos períodos de guerra em que a Alemanha esteve envolvida na primeira metade do século XX. Com o início da guerra de 1914, entre a Tríplice Aliança (Itália, Império Austro-Húngaro e Alemanha) e a Tríplice Entente (França, Rússia e Reino Unido), os problemas, para esses estrangeiros, foram preocupantes. O Correio da Tarde, de 07 de novembro de 1917, noticiou, em primeira página, o apedrejamento de algumas casas possivelmente ligadas a imigrantes alemães, que haveria ocorrido dois dias antes:

\section{Os apedrejamentos de ante-hontem}

Ainda hoje se veem os vestígios das violências commetidas pelos populares contra diversas casas suspeitas de homisiarem allemães ou bens allemães. Assim, a Bombonière Suissa, à Rua da Bahia, mostra signaes de apedrejamen- 
to. A casa Wilke está, também, com a frente toda estragada, acontecendo o mesmo com outros prédios da avenida Afonso Pena e da rua Caetés. Onde, porém, a multidão mais se excedeu foi na Padaria Schiniger, que foi apedrejada e violentamente invadida, ante-hontem, sendo impotente a polícia para conter o povo (CORREIO da Tarde, 07/11/1917, p.1).

Durante a primeira Guerra Mundial, o CCAA foi invadido ${ }^{19}$ por acadêmicos do curso de Medicina da capital mineira. Aqueles futuros médicos acreditavam que os clérigos da CVD poderiam constituir alguma ameaça à comunidade local, mesmo sem elementos concretos que pudessem indicar que os padres daquele educandário apoiassem os motivos bélicos alemães. Não foi encontrado qualquer indício material que pudesse apresentar, com maior clareza, o que motivou tal invasão. A hipótese que se pode aventar, a respeito do motivo que poderia ter impulsionado esses estudantes de Medicina a cometerem essa investida contra o educandário católico, estaria no fato, anteriormente mencionado, de ter havido o indeferimento ao intuito do Dr. Hugo Werneck de destinar o local, com o qual a escola foi contemplada pela Prefeitura, à edificação de uma Faculdade de Medicina.

Diante do fato, houve a intenção de se entregar, por parte dos padres alemães, o comando do Colégio ao Presidente do Estado, mas este julgou que não seria necessário. Foi nomeado um fiscal para um regime especial de inspeção, o Dr. Cicero Ferreira ${ }^{20}$ diretor da Escola de Medicina e um dos chefes do movimento que invadiu o CCAA. Os acadêmicos não se contentaram com isso, invadindo o Colégio novamente e colocando os padres na rua. Com o passar dos tempos, o Arcebispo de Mariana providenciou a reabertura da instituição, colocando na direção um brasileiro, o Dr. Lúcio dos Santos, professor da Escola de Minas de Ouro Preto, conhecido em todo o estado e um dos professores que mais aparece nas publicações desse Colégio. Esse personagem tomou providências para a reabertura, porém os Drs. Borges da Costa e Estevam Pinto, amparados por Mendes Pimentel, não concordaram com a nova direção, por considerar o professor Lúcio dos Santos "germanophilo conhecido e perigoso". ${ }^{21}$ Foi nomeado o Cônego João Pio de Souza Reis, sob cuja direção o Colégio, fechado em finais de 1917, voltou a funcionar em março de 1918 (JORNAL do CCAA, jun. 1937, p.13).

Nos jornais do final da década de 1910, aparecem notícias sobre hostilidades ocorridas por parte da população mineira em direção aos 
estrangeiros ligados à guerra e domiciliados em Belo Horizonte. A presença de notícias como essas não foi encontrada em nenhum dos jornais de grande circulação consultados para compor esta pesquisa, durante o período do Estado Novo, ${ }^{22}$ sendo que é nesse mesmo período que ocorre a Segunda Grande Guerra, influenciando as políticas de nacionalização do ensino brasileiro, como citado anteriormente. Nenhuma nota foi encontrada que publicasse alguma ocorrência do mesmo gênero das encontradas em jornais durante o período da Primeira Guerra Mundial. Atribui-se essa ausência ao fato de este período (1937-1945) compreender um momento em que o governo mantinha forte controle sobre os meios de comunicação $0^{23}$ no Brasil, não sendo interesse daquele governo que notícias envolvendo desordem pública fossem veiculadas e levadas ao conhecimento geral da população.

Durante o período da Segunda Grande Guerra, o fato de os padres da CVD serem de proveniência alemã acabou por lhes render muitas ligações com a Alemanha de Adolf Hitler, atribuindo a eles supostas aproximações com os ideais nazistas. São fatores que colocavam os referidos clérigos na posição de inimigos da comunidade mineira, mais especificamente da capital. Essa população acaba por gerar para o outro, nesse caso, os alemães em Belo Horizonte, uma identidade étnica instituída a partir da diferença. A convivência que naturalmente é estabelecida entre os que se reconhecem como locais, no caso, a população de Belo Horizonte, é indissociável da repulsa por aqueles que são percebidos como estrangeiros. Nesse caso, a condição que foi atribuída a esses estrangeiros, como pode ocorrer em casos similares, não foi fruto de um isolamento e da criação de uma simbologia de pertencimento comum, mas, sim, do estabelecimento de diferenças das quais os indivíduos se apropriam para instituir fronteiras étnicas, pois as relações desses sujeitos históricos com a comunidade da capital mineira sempre foram muito próximas, por meio de sua escola e de sua capela, ambas abertas à frequentação de toda a população mineira.

Parece que os sujeitos do CCAA, durante os anos 1937 a $1945,{ }^{24}$ se colocaram perante a sociedade mineira de forma a não querer viver novamente algo como o que aconteceu em 1917. Muito foi feito para que a imagem da instituição escolar não fosse atribuída novamente aos ideais bélicos alemães. Apesar desse esforço, não deixaram de ocorrer diversos eventos problemáticos. O primeiro exemplo disso é relativo à constatação 
de que o CCAA sempre procurou mostrar-se compromissado com os ideais do governo brasileiro no momento da Segunda Guerra Mundial. Apesar da proveniência alemã de toda a sua administração clerical, e mesmo com o seu país de origem estando politicamente em lado oposto em relação ao conflito mundial, buscou esta se empenhar em levar a instituição e todos os seus sujeitos a participar na Campanha Nacional da Aviação Brasileira (CNAB) ${ }^{25}$

Não bastava apenas que o Colégio integrasse a ação patriótica do governo. Por meio de solenidades com a presença de autoridades externas e em seus discursos, como constatado em suas publicações que serviram de fontes para esta pesquisa, não houve nenhum constrangimento por parte dos sujeitos da instituição em querer demonstrar e registrar explicitamente o compromisso do Colégio com a nação brasileira. Isso, apesar de sua direção ser estrangeira e proveniente de um dos países participantes do conflito que se arrolava naquele momento. Além do mais, país esse, considerado, naquele momento, como inimigo da nação brasileira.

O receio que se abateu sobre os padres da CVD parece ter sido tão intenso, que, de alguma forma, a postura adotada pelos clérigos alemães chegou a contrariar um dos mais fortes termos de sua cultura: Deutschtum ou jus sanguinis. Gustavo Tentoni Dias (2006), falando sobre a formação étnica dos teuto-brasileiros, aborda características da cultura alemã. O termo alemão Deutschtum seria definido como uma categoria referente à nacionalidade do povo alemão especificamente. Ele define os traços culturais particulares desse grupo, ${ }^{26}$ demonstrando suas crenças, regras de conduta e os valores morais responsáveis pela organização de seu universo.

O que interessa, nesse elemento cultural, é que esse ordenamento de significados estabelece como cada indivíduo originário da Alemanha deveria situar-se em qualquer parte do planeta para onde se transferisse. Em qualquer parte do mundo, o alemão imigrante deve, de acordo com esses preceitos, preservar os traços culturais que constituem o Deutschtum. Esses traços devem ser transmitidos através das novas gerações pelas vias da educação escolar, dos ensinamentos religiosos e pela educação recebida no lar. Assim, ao professor, ao pastor e aos pais se atribuiria a função de atualizar constantemente o passado no presente, graças à capacidade de relatarem não só os conhecimentos adquiri- 
dos socialmente, mas também a experiência de vida acumulada durante as suas existências particulares.

Conforme Giddens (1991), a transmissão dos valores nacionais, dos mitos históricos e das tradições folclóricas alemãs é responsável pela atualização constante das crenças culturais com o intuito de estabelecer uma coesão social. O Deutschtum deveria atuar criando padrões cíclicos, responsáveis por acumular passado, presente e futuro, de forma homogênea. De acordo com esse padrão cultural, deveria haver uma conservação dos traços culturais e dificilmente alterados, com o passado preservando referências míticas, o presente atualizando-as por meio de rituais, resguardando a cultura alemã em qualquer lugar onde este povo se encontre. Deutschtum, na sua relação étnica nacionalista, prescreveria que a nacionalidade alemã é herdada pelo sangue (jus sanguinis) e perpetuada, mesmo longe da pátria de origem, por meio da cultura, do idioma e dos demais costumes alemães. Ou seja, o alemão continuaria pertencente e fiel à sua nacionalidade de origem, esteja ele onde estiver localizado geograficamente, mesmo que fora de seu território pátrio.

Apesar de todo o empenho do CCAA em mostrar seu total apoio à nação brasileira e nenhum alinhamento com o seu país de origem, os padres da CVD não deixaram de viver experiências consideradas amargas. A edição do jornal do CCAA (ano XIII, n.2, de maio de 1944, p.21), com o título "Motivo de satisfação", trouxe a grata notícia à comunidade do Colégio da libertação do Monsenhor Manuel Koenner, ${ }^{27}$ seu ex-diretor, que teria sido preso aqui no Brasil, no ano anterior (1943).

Essa segunda e última ilustração aqui apresentada teria abalado profundamente a comunidade do Colégio à época. Segundo a pequena nota, que não informa o motivo da acusação e da consequente prisão, o padre foi colocado em liberdade por ter sido considerado inocente "perante as autoridades, que, por motivo de prevenção, e apenas suspeita, o detiveram". A explicação parcial para tal fato foi obtida nesta pesquisa pela reportagem encontrada no jornal Folha de Minas:

Sem fundamento as acusações feitas ao Monsenhor Manuel Koenner Absolvido pelo Tribunal de Segurança aquele virtuoso prelado, antigo Diretor do Colegio Arnaldo da capital - A verdade em torno do material do Arquiduque de Habisburgo, encontrado na Prelazia de Foz do Iguassú (FOLHA DE MINAS, 20/02/1944, p.7). 
Conforme a reportagem do jornal Folha de Minas, o clérigo foi envolvido em suspeitas de atividades nazistas desenvolvidas em Foz do Iguaçu. A imprensa o apontou à época como "Perigoso agente do Reich alemão a tal ponto de guardar em Foz do Iguassú, de que era prelado, material trazido ao Brasil pelo Arquiduque Albrecht Von Habsburg". Monsenhor Manuel Koenner foi denunciado ao Tribunal de Segurança Nacional, que nada teria encontrado para comprovar as acusações realizadas. Com sua libertação, teria ficado provado que "todo o material encontrado na prelazia de Foz do Iguassú pertencia ao Arquiduque de Habsburg e entrara no Brasil com pleno consentimento de nossas autoridades". A conclusão foi a de que, quando o material, que não é descrito pela reportagem, chegara à prelazia, Monsenhor Manuel Koenner ainda morava em Minas Gerais, não era prelado naquela localidade, sendo assim, as acusações contra ele não teriam fundamento, como informa o jornal.

Diante dos fatos levantados pelo Tribunal, nada haveria por se fazer além de absolver o ex-diretor do CCAA. A notícia não apresenta a relação do suposto material nazista, nem mesmo cita o gênero ou a natureza dele. Supõe-se, então, que esse material possa ter relação com "rádioemissoras clandestinas" brevemente citadas na reportagem intitulada " $\mathrm{O}$ caso de 'O Radical"'.28

Dentro da configuração desse artigo, que envolveu uma escola constituída por estrangeiros, na figura de missionários religiosos, para esses "recém-chegados", houve a construção de uma condição semelhante à de outsiders. Condição elaborada, em alguns momentos, de maneira cultural, e, em outros, de maneira política. Nesse caso, uma atribuição fundamentada no fato de os clérigos alemães serem provenientes de um país belicamente inimigo e de alguma forma os alocando na posição de ameaçadores de uma ordem local que se percebia como estável, pois "os estabelecidos procuram preservar o status superior que os recém-chegados parecem ameaçar" (ELIAS; SCOTSON, 2000, p.174).

Pode-se ilustrar essa proposição com os problemas vivenciados pelos missionários alemães, que, apesar de católicos, inserindo-se em uma comunidade tradicionalmente católica, foram relegados a uma posição de inimigos brasileiros em determinado momento, considera-se que mais política que culturalmente, mas com a primeira influenciando a segunda. Assim, esses atores sociais viveram contratempos e dificuldades em fun- 
ção das duas guerras que envolveram a nação de que provinham. Nesse caso, "como os estabelecidos costumam ter uma integração maior e ser mais poderosos, eles conseguem, através da indução mútua e da colocação dos céticos no ostracismo, dar uma sólida sustentação a suas crenças" (ELIAS; SCOTSON, 2000, p.175). Essa "indução mútua", vale ressaltar, foi bastante estimulada contra o elemento estrangeiro no ambiente político dos anos 1930 e 1940, no Brasil.

\section{Considerações finais}

Com este trabalho, buscou-se realizar uma interpretação histórica da cultura escolar de uma instituição de ensino que marcou significativamente a história educacional da cidade de Belo Horizonte. Acredita-se que as práticas desenvolvidas nessa instituição escolar são semelhantes às das demais escolas privadas de mesma confissão religiosa, organizadas na primeira metade do século XX. O que, de fato, configurou a experiência do Colégio Arnaldo Jansen como singular evidencia-se nas relações conflituosas e nas influências junto à comunidade mineira devido às interferências políticas e culturais suscitadas pelos dois conflitos bélicos de ordem mundial do período estudado.

A maior parte dos trabalhos relacionados com a presença dos estrangeiros em Belo Horizonte volta-se para o estudo das experiências vividas pelos italianos. Buscou-se, também, com esta pesquisa, referenciar a presença de outros grupos estrangeiros na cidade, representados, neste artigo, pelos clérigos de proveniência alemã.

O receio que se abateu sobre os padres da CVD demonstra ter sido de tal intensidade, que, de alguma forma, a postura adotada pelos clérigos alemães parece contrariar um dos mais fortes termos de sua cultura: Deutschtum ou jus sanguinis. Mesmo com todo o empenho em se mostrar, por parte dos sujeitos do CCAA, um total apoio à nação brasileira e nenhum alinhamento com o seu país de origem, os padres da CVD não deixaram de experimentar dissabores ao tentarem estabelecer-se na comunidade belorizontina.

Ao realizar as devidas análises documentais demandadas por esta investigação, emergiram assuntos importantes que merecem a realização de trabalhos que os elejam como objetos de análise. No meu entender, 
esta pesquisa assume, entre outras, a característica de servir a novas possibilidades de investigação em relação à instituição de ensino estudada, além de sua mantenedora confessional, sendo que essa questão, como constatado, ainda não foi abordada historiograficamente de forma aprofundada. São muitas as possibilidades de estudos que poderão contribuir para as histórias da educação, educação ligada a estrangeiros e à religiosidade, escolas privadas e da própria cidade de Belo Horizonte.

\section{NOTAS}

1 No ano de 1875, mais precisamente no dia 08 de setembro, seguido por alguns jovens religiosos, o padre alemão Arnaldo Jansen se envolveu na tarefa de difundir a fé cristã, instituindo, na Holanda, a Congregação do Verbo Divino. Mais informações sobre a CVD, consultar SANTOS (2010).

2 Ministério da Educação e Saúde, Departamento Nacional de Educação, Divisão de Ensino Secundário, entre outros.

3 As Congregações Religiosas desenvolveram, e ainda desenvolvem, importante e intenso trabalho educativo na capital mineira. Pode-se perceber essa intensidade no considerável número de instituições de ensino construídas e mantidas por religiosos provenientes de diversas partes do mundo.

4 A grande maioria das escolas particulares e particulares confessionais ocupou espaçosos terrenos concedidos e foi instalada em edificações consideradas, algumas, ainda nos dias atuais, como verdadeiros monumentos da arquitetura. Essa monumentalidade se faz plenamente perceptível diante da grande precariedade na qual se instalava a maioria das escolas de ensino elementar próximas a Belo Horizonte e do esforço na construção de grupos escolares bem equipados e em áreas centrais.

5 Ver KREUTZ, 2000a, 2000b e 2004.

6 Norberto Bobbio considera que o termo nacionalismo designa a ideologia nacional de determinado grupo político, o Estado nacional que se sobrepõe às ideologias dos partidos, absorvendo-as (BOBBIO, 1995, p.798).

7 O imaginário permeia as habilidades de elaborações e representações culturais dos seres históricos como capacidade humana para representação do mundo em que se vive, conforme Baczko (1985).

8 Povos entendidos como o conjunto de pessoas que falam a mesma língua, têm costumes e interesses semelhantes, história e tradições comuns.

9 Para uma referência nacional, a antropóloga luso-brasileira Maria Manuela Ligeti Carneiro da Cunha (1986), em Antropologia do Brasil: mito, história, etnicidade, analisa a "substância da etnicidade", trazendo uma reflexão a partir do termo etnicidade e 
suas transformações, através das diversas temporalidades. Partindo dos debates do século XIX, ela pretendeu demonstrar como a etnicidade passou a ser entendida por um fenômeno cultural. Sendo cultura, inculcada e não adquirida biologicamente, esta também pode ser perdida.

10 Fredrik Barth é um dos autores mais citados, contudo, menos lido pelos antropólogos. Barth foi uma das figuras mais "cheias de vida" da antropologia social britânica dos anos 50 e 60. No entanto, a acolhida da obra barthiana nem sempre foi tão unânime e fervorosa. Indo além das opiniões diversas, o certo é que as teses de Barth suscitaram grandes discussões, transformando-se em um marco para a antropologia (VILLAR, 2004, p.165).

11 Sobre nacionalização do ensino durante a Primeira Guerra Mundial, consultar: OLIVEIRA, Lúcia Lippi. A questão nacional na Primeira República. São Paulo: Brasiliense, 1990.

12 Por assimilação étnica, Rodrigues (2009) entende como um processo de tornar semelhante, igual; de interpenetração e fusão de culturas (tradições, sentimentos, estilos de vida) em um tipo cultural comum; também por um processo de integração do imigrante ao país que o recebeu e onde este reside.

13 Já no período republicano, em 1890, é fundado o Instituto Granbery na cidade de Juiz de Fora. A ruptura entre Estado e Igreja Católica facilitou o aparecimento de escolas confessionais e outras instituições de diversas orientações religiosas. Originário dos Estados Unidos da América, o Granbery trouxe um ideário liberal, e seu projeto educativo se identificava com os princípios democráticos e com a ética protestante. Esses elementos despertavam o "interesse de uma significativa parcela da população brasileira” (YAZBECK, 1999, p.33).

14 Até àquele momento, haviam sido construídos apenas os alicerces para a estrutura do citado "prédio".

15 Cf.: SANTOS, 2010, p.95.

16 No texto assinado pelo professor Mário de Lima, Festa de encerramento do anno lectivo, o autor cita os colegas de instituição com suas respectivas atuações na educação do Estado de Minas Gerais: "Dr. Lucio dos Santos, professor da Escola de Minas de Ouro Preto; Dr. Antonio Affonso de Moraes, director da Secretaria de Polícia e Dr. Francisco de Magalhães Gomes, professor da Escola de Medicina e da Escola Normal Modelo de Bello Horizonte - todos elles mestres provectos, e nomes consagrados no magisterio superior e secundario do Estado" (IMPRENSA Official, 1920 , p.66).

17 Este livro de atas é iniciado em 1921. Desde essa data, o livro foi preenchido em língua alemã, perpetuando as escrituras em alemão até fins de 1944. O primeiro registro em português aparece apenas em 21/04/1945, sendo assinado pela mesma pessoa que assinava os registros em alemão, durante o ano de 1944. Os assuntos/resoluções são registrados de maneira direta e objetiva, não havendo todo um protocolo detalhado para a abertura das sessões das reuniões. Nesse livro, os registros das discussões realizadas são apresentados de forma direta, relatando as decisões de professores do 
CCAA, tomadas em cada reunião. Essas conclusões são a partir do primeiro registro em português, em 21/04/1945, indo até o último, em 02/11/1954.

18 Com esse termo, deseja-se dizer que essa dissidência política foi atribuída a esses clérigos alemães pela população local, baseada no fato de esses sujeitos provirem de um país que se encontrava na condição de belicamente hostil, para aquele momento histórico. Não foi encontrado qualquer indício material que mostrasse que os padres do Colégio Arnaldo Jansen apoiavam os motivos bélicos de seu país de origem.

19 Em uma das conversas com a atual direção do Colégio para se obter a devida permissão de acesso aos arquivos históricos da instituição, obteve-se a informação de que "toda a documentação" existente até 1917 referente às atividades do colégio "foi destruída" nessa invasão.

20 Documento solicitando inspeção, emitido pelo Secretário do Interior Dr. Américo Lopes, com instruções ao Sr. Cícero Ferreira, em 03/11/1917.

21 Esse episódio da trajetória de existência dessa instituição de ensino de Belo Horizonte permanece na memória de várias gerações em nossa cidade, principalmente das pessoas que têm alguma proximidade com o Colégio, ou ex-alunos e familiares desses que viveram naquela época. Alguns dos detalhes aqui apresentados são provenientes de um recorte de jornal que faz parte do acervo documental do CCAA, com o título, "De Bello Horizonte" e foi assinado por Souza Pinto. Durante o período de pesquisa, buscou-se identificar a proveniência desse recorte, ou de que órgão da imprensa proveio esse fragmento, porém não se obteve sucesso nessa identificação. Em Mourão (1962, p.501), consta uma breve informação a respeito dessa invasão ocorrida no ano de 1917.

22 Foram consultados, no período de 1937 a 1945, os jornais Estado de Minas, Folha de Minas e em menor proporção o Minas Gerais, devido a este último não se mostrar fértil para o objetivo de pesquisa com os jornais. O objetivo principal foi o de perceber as repercussões noticiadas pelos jornais quanto aos estrangeiros e suas escolas durante o governo autoritário brasileiro e durante a Segunda Guerra Mundial, entre outras observações.

23 O controle da imprensa foi estabelecido não somente pela censura, mas ocorreram também influências políticas e financeiras. Algo como o praticado na Itália fascista de Mussolini, no Brasil, vários assuntos e notícias eram totalmente proibidos pelo DIP (Departamento de Imprensa e Propaganda), como as que apresentassem ou apenas sugerissem descontentamento e oposição ao regime varguista.

24 Período que compreendeu o Estado Novo, com seus ideais nacionalistas mais exacerbados, momento em que ocorre também a Segunda Guerra Mundial, tendo novamente a Alemanha envolvida no conflito.

25 Essa campanha foi uma organização do governo Vargas, idealizada pelo jornalista Assis Chateaubriand, então proprietário dos jornais que compunham os Diários Associados, fazendo parte dessa cadeia o jornal Estado de Minas. A campanha realizada durante a década de 1940 objetivou levantar doações de aviões, dinheiro ou materiais que contribuíssem para a compra ou a construção de aeronaves, hangares e campos 
de pouso e decolagem. Outro objetivo dessa campanha foi o de estimular a existência de aeroclubes como forma de realizar uma consolidação da aviação civil brasileira.

26 Língua, religião e sistema de parentesco.

27 A referência a esse clérigo, integrante do Colégio Arnaldo Jansen, foi substituída, na dissertação, pelo nome de Monsenhor K. devido à necessidade do sigilo em relação aos sujeitos da instituição.

28 Página de número 21 da edição ano XIV, número 2, de agosto de 1945 do jornal do CCAA, descreve, de maneira um pouco confusa, sobre um missionário de Foz do Iguaçu, que, de maneira equivocada, foi atribuído ao caso de "rádio-emissoras clandestinas" no CCAA em Belo Horizonte.

\section{REFERÊNCIAS}

ANDERSON, Benedict R. O. G. Comunidades imaginadas: reflexões sobre a origem e a expansão do nacionalismo. Lisboa: Edições 70, 2005.

BACZKO, Bronislaw. Imaginação social. In: ENCICLOPÉDIA Einaudi. Lisboa: Imprensa Nacional; Casa da Moeda, 1985. v.5.

BARTH, Fredrik (Org.). Los grupos étnicos y sus fronteras. México: Ed. Fundo de Cultura Económica, 1976.

BOBBIO, Norberto et al. Dicionário de política. 7.ed. Brasília: UnB, 1995. v.2.

BUFFA, Ester; NOSELLA, Paolo. As pesquisas sobre instituiçoes escolares: um balanço crítico. Anais do VI Congresso Luso-brasileiro de História da Educação, Uberlândia-MG, 2006.

CANÇADO, José Maria. Colégio Arnaldo: uma escola nos trópicos. Belo Horizonte: Ed. C/ Arte, 1999.

CUNHA, Manuela Carneiro. Antropologia do Brasil: mito, história, etnicidade. São Paulo: Brasiliense, 1986.

CURY, Carlos Roberto Jamil. O público e o privado na história da educação brasileira: concepções e práticas educativas. In: LOMBARDI, José Claudinei, JACOMELI, Mara Regina M. e SILVA, Tânia Mara T. (Org.). O público e o privado na bistória da educação brasileira: concepções e práticas educativas. Campinas: Autores Associados, 2005.

DIAS, Gustavo Tentoni. Cultura, política e alfabetização no Brasil: a 'segunda campanha de nacionalização’ do ensino (1938-1945). 2006. 219f. Dissertação (Mestrado em Ciências Sociais), UFSCar, São Carlos, 2006.

ELIAS, Norbert; SCOTSON, John L. Os estabelecidos e os outsiders. Rio de Janeiro: Zahar, 2000. GELLNER, Ernest. Nações e nacionalismo. Lisboa: Gradiva, 1993.

GIBERNAU, Montserrat. Nacionalismos: o estado nacional e o nacionalismo no século XX. Rio de Janeiro: Jorge Zahar, 1997.

GIDDENS, A. Consequências da modernidade. São Paulo: Ed. UNESP, 1991.

IMPRENSA Official do Estado De Minas. Annuario do [CCAA] de Bello Horizonte. Belo Horizonte: Imprensa Official, 1920. 
JULIA, D. A cultura escolar como objeto histórico. Revista Brasileira de História da Educação, Campinas, n.1, p.9-44, 2001.

KREUTZ, L. A Educação de imigrantes no Brasil. In: LOPES, Eliane Marta Santos Teixeira (Org.). 500 anos de educação no Brasil. 2ed. Belo Horizonte: Autêntica, 2000a.

KREUTZ, L. Escolas comunitárias de imigrantes no Brasil: instâncias de coordenação e estruturas de apoio. Revista Brasileira de Educação, Rio de Janeiro, n.15, p.159-176, set./out./nov./dez, 2000b.

KREUTZ, L. Professor paroquial: magistério e imigração alemã. Pelotas: Seiva, 2004.

LAR Católico. Jubileu Aureo: $50^{\circ}$ Aniversário da chegada dos primeiros Missionários da Congregação do Verbo Divino ao Brasil. Juiz de Fora: Tipografia do "Lar Católico", 1945.

MAGALHÃES, Justino. Um apontamento metodológico sobre a história das instituições educativas. In: SOUSA, Cynthia Pereira de; CATANI, Denice Bárbara (Orgs). Práticas educativas, culturas escolares, profissão docente. São Paulo: Escrituras, 1998.

MOURÃO, Paulo Kruger Corrêa. O ensino em Minas Gerais no tempo da República. Belo Horizonte: Centro Regional de Pesquisas Educacionais, 1962.

OLIVEIRA, Lúcia Lippi. A questão nacional na Primeira República. São Paulo: Brasiliense, 1990.

PIMENTEL, Thais Velloso Cougo. De outras terras, de outro mar. experiências de imigrantes estrangeiros em Belo Horizonte. Belo Horizonte: Museu Histórico Abílio Barreto, 2004.

POUTIGNAT, Philippe; STREIFF-FENART, Jocelyne. Teorias da etnicidade: seguido de grupos éticos e suas fronteiras de Fredrik Barth. São Paulo: UNESP, 1998.

RODRIGUES, Maysa Gomes. Sob o céu de outra pátria: imigrantes e educação em Juiz de Fora e Belo Horizonte, Minas Gerais (1888-1912). 2009. 401f. Tese (Doutorado em Educação), Faculdade de Educação da UFMG, Belo Horizonte, 2009.

SANTOS, Hercules Pimenta. Católicos e protestantes: escolas confessionais fundadas por missionários estrangeiros, Belo Horizonte - MG (1900-1950). 2010. 206 f. Dissertação (Mestrado em Educação), Faculdade de Educação da UFMG, Belo Horizonte, 2010.

VEIGA, Cynthia G.; RODRIGUES, Maysa G. Etnicidade e história da educação. In: MORAIS, Christianni Cardoso; PORTES, Écio Antônio; ARRUDA, Maria Aparecida. História da educação: ensino e pesquisa. Belo Horizonte: Autêntica, 2006.

VILLAR, Diego. Uma abordagem crítica do conceito de "etnicidade" na obra de Fredrik Barth. Mana [online], v.10, n.1, p.165-192, 2004.

YAZBECK, Dalva Carolina de Menezes. As origens da Universidade de Juiz de Fora. Juiz de Fora: Editora UFJF, 1999. 
Recebido: 23/07/2012

Aprovado: 05/08/2013

Contato:

Departamento de Ciências Aplicadas à Educação

Faculdade de Educação

Universidade Federal de Minas Gerais

Avenida Antônio Carlos, 6627

Pampulha

CEP $31270-901$

Belo Horizonte | MG | Brasil 